\title{
Public understanding of environment and bioenergy resources*
}

\author{
Gauhar Raza, P.V.S. Kumar, Surjit Singh
}

\begin{abstract}
There exists a distinct disconnect between scientists' perception of nature and people's worldview. This 'disconnect' though has dialectical relationship with science communication processes which, causes impediments in the propagation of scientific ideas. Those ideas, which are placed at large cultural distance, do not easily become a part of cognitive structure of a common citizen or peoples thought complex. Low level of public understanding of bio-energy technologies is one such sphere of understanding. The present study is based on assumption that public debate on bio-energy is part of the larger human concern about climate change. In this paper we present meta-analyses from published literature and take a look at the surveys that have been carried out at national and international level. In the second section of the article we also present analysis of the survey study carried out in India and locate the shifts in public understanding of science.
\end{abstract}

\section{Introduction}

Humans have used biomass for food, fodder and fuel from time immemorial. Bioenergy refers to the energy derived from plants and crops for heating, cooking, and transporting men and materials. Traditionally societies depended on the plant-derived energy for cooking or heating the households (e.g through wood burning). Discovery and development of mineral based fuels soon replaced plant based fuels for cooking, transportation and heating of the habitat etc. as the economic growth took place among the nations and within nations across socio-economic classes. Economic growth through rapacious use of mineral based energy resources (such as coal and oil) have prompted the societies to the environmental externalities that such a mode of economic growth have become unsustainable. ${ }^{1}$ Nation states and international organizations have now stressed the importance of environmental protection and need for conservation and growth of biotic resources - particularly the forests and plant diversity. ${ }^{2}$ The recent advances in the knowledge of adverse climatic changes due to emissions 'green house gases (GHGs) particularly the $\mathrm{CO}_{2}$ have re-focused the attention of policy makers and consumers to the importance of 'renewable' sources of energy- particularly 'converted bioenergy' sources such as biofuels,(bio-diesel bio-ethnol and bio-gassification). The non-commercial traditional uses of bio-energy sources such as fuel wood, chips and dung cakes, contribute around $30 \%$ of the total primary energy consumption (dominated by coal and imported oil) mainly for cooking and space heating applications in rural areas. According to an estimate about 2.5 billion of the worlds poorest people rely on these non-commercial bioenergy sources every day contributing up to $80 \%$ of total energy requirement of some rural communities. ${ }^{3}$

Bioenergy is also called variously as 'green energy' sustainable energy' and 'alternative energy' to distinguish these from the current energy sources - mostly the fossil fuel based energy sources. Thus a shift in the use of plant based energy resources took place, from direct usage such as fuel wood to converted products such as bio-diesel, bio-gas etc. The converted energy usage is generally labelled as bio-energy in developed countries, while the direct usage of plant based energy is rarely labelled or understood as bio-energy, particularly where such usage is widespread in developing countries.

\footnotetext{
* An earlier version of this paper was presented at the Public Environment Network (PEN) Conference held at Gaborone Botswana during October 20, 2010.
} 


\section{Paradigm shift}

It is a huge paradigmatic change in the perception of mankind when people realized that nature needs to be 'nurtured / managed' rather than just be r(e)aped for the benefit of humankind This realization is at the heart of our current understanding and valuation of bio-energy resources and their management.

The potential benefits of bioenergy include: reduction of greenhouse gases, recuperation of soil productivity and degraded land, economic benefits from adding value to agricultural activities and improving access to and quality of energy services. Biomass is an abundant and underutilized resource, which remains to be effectively used on a commercial and societal scale. Green plants produce an estimated 1 trillion metric tons of cellulose every year. Using even a fraction of this for bio-ethanol and biogas could begin to reduce our yearly addition of more fossil carbon to the atmosphere, curbing global warming, and providing additional domestic energy supplies and jobs. Worldwide, the use of bioenergy could provide social and economic benefits to many countries and reduce their dependence on imported oil, while lowering their emissions of $\mathrm{CO}_{2}$ from fossil carbon.

\section{Bioenergy in relation to climate change}

While the science of global warming is building up, the 'action space' on prognosis of this hazard started sometime in the 1990s with the Earth Summit in Rio de Janeiro, Brazil. Basically the problems caused by global warming was sought to be addressed by two mechanisms (1) mitigation and (2) adaptation.

Mitigation refers to "(T)echnological change and substitution that reduce resource inputs and emissions per unit of output. Although several social, economic and technological policies would produce an emission reduction, with respect to Climate Change, mitigation means implementing policies to reduce greenhouse gas emissions and enhance sinks". These strategies mean increasing 'green cover' to absorb the $\mathrm{CO} 2$ emissions - by way of afforestation and use of bio-energy to as 'carbon sinks'

Adaptation refers to "(I)nitiatives and measures to reduce the vulnerability of natural and human systems against actual or expected climate change effects. Various types of adaptation exist, e.g. anticipatory and reactive, private and public, and autonomous and planned. Examples are raising river or coastal dikes, the substitution of more temperature-shock resistant plants for sensitive ones, etc.",

\section{Public space}

The domain of environment has remained a matter of concern for everyone for more than a decade. Politicians, environmentalists, scientists, social workers, etc, have been talking about the environmental degradation, deforestation, industrialization and urbanization, all matters of concern for the existence of human life on the planet. Slogans like 'say no to plastic', 'save the planet earth', 'plant more trees' etc. have been used to make people aware and project like 'Ganga Action Plan' was started by government of India to bring forth the environmental issues in the political agenda. School and college syllabi have been modified to include environment and environmental pollution as major subjects and allocation of funds for the research in the areas increased.

Climate change has now become a buzzword in the academic and political communities. But how far this scientific concept has percolated down to public is a moot point. The important producers of academic knowledge - international institutions such as Inter-Governmental Panel on Climate Change (IPCC), various national academies of science, universities and research institutes - regularly publish the brochures and newsletters, which contain non-technical findings of their work in climate, change. Much of this literature is reproduced and interpreted by mass media - whether in print or electronic channels. ${ }^{5}$ Regular surveys have also been conducted on public perceptions on climate change among lay public in various countries. ${ }^{6}$

Public understanding and their involvement is essential for future of the world to counteract some of the negative impacts of climate change. The public as citizens are entitled to the policy making on climate change - even if they cannot participate or influence its content. The public needs to be informed of the adaptation strategies of the state and non-state actors in the event of actual or expected hazard due to climate change - such as floods, drought, or cyclones. It is for this purpose unambiguous understanding and unequivocal cause-effect of climate change is necessary to be communicated to the public. Scientists 
need to know how the public is likely to respond to climate impacts or initiatives, because those responses can attenuate or amplify the impacts.

Mass media and other interpersonal channels are expected to perform the mediating role between the scientific communities and the public. The academic specialization of public understanding of science deals with two aspects - (1) the communicating role of the media and other channels to diffuse the science as well as (2) the extent of understanding (cognitive, affective and behavioural dimensions) of scientific concepts and methodologies among lay public. Climate change involves hazards and risk to vulnerable population - therefore it involves communicating risk to the target population.

\section{Bio-energy in India}

Historically, traditional biomass has been a major source of household energy in India - about 78 percent of rural households use biomass for their energy needs, while in urban areas only 20 percent use biomass for their energy requirements. ${ }^{8}$ Currently, about 40 percent of the total energy supply in India is from non-commercial energy sources such as wood and cow dung. Rural households in India predominantly use wood and cow dung as fuel for cooking and water heating due to lack of reliable supply of electricity or cooking gas. Modern biomass energy is derived from organic material and can be used in a variety of conversion processes to yield power, heat / steam, and fuel. In India, the renewables' use is focused on waste materials such as municipal, agricultural, or forest residues. Biomass is generally divided into three categories: biogas, solid biomass, and liquid biofuels.

Biogas has been mostly used for small, rural, and off-grid applications, and the majority of gasifiers in India are providing for individual households. About 4 million family-size biogas plants were installed in India and Indian Government's Ministry of New and Renewable Energy (MNRE) estimates that the annual biogas generation potential is about 17,340 million cube meters (m3), which could support the installation of up to about 12 million family-size biogas plants. Larger scale biogas facilities use wastewater generated from beverage, meat processing, pulp and paper, food packaging, and other industrial sectors which together produce about $91 \mathrm{MW}$ equivalent of electricity. Another 73 medium biogas plants with aggregated capacity of $461 \mathrm{~kW}$ have been installed under Distributed/Grid Power Generation Program of the Ministry.

Indian Government adopted a National Policy on Biofuels in December 2009. ${ }^{9}$ Indian government's biofuel strategy is currently focused on using non-food feedstock for the production of biofuels, mainly sugar molasses and non-edible oils. The Indian approach to biofuels, in particular, is somewhat different to the current international approaches which could lead to conflict with food security. It is based solely on non-food feedstocks to be raised on degraded or wastelands that are not suited to agriculture, thus avoiding a possible conflict of fuel vs. food security. As a part of this policy, the government extends the minimum support price (MSP) to non-edible oil seeds for production of ethanol. The commercial production of biodiesel is very limited, and what is produced is mostly sold to the unorganized rural sector. The existing biodiesel producers in India are using non-edible oilseeds, non-edible oil waste, animal fat, and used cooking oil as feedstock.

\section{Attitudes towards bio-energy}

Report of the two survey studies on 'Improving the Public Perception of Bioenergy in the EU' by Harald Rohracher, et al., begins with an assertion that 'It is widely acknowledged that the diffusion of technologies in general, and the use of bioenergy in particular, does not depend on technological advances and favourable economic conditions alone'. ${ }^{10}$ Acknowledgement of the fact that attitudes and perceptions clubbed with cultural dimensions play an equally important role in successful introduction of a technological project is not something new. However, recognition of the fact that peoples perceptions and attitudes should be measured and studied while introducing technologies is a recent practice.

Study of public understanding of science and technology becomes imperative specially, for ensuring success of those technologies where without participation of communities implementation and diffusion cannot take place. ${ }^{11}$ Bioenergy is one such area. The word 'bioenegry' in public arena connotes multifaceted notions. For example those working on high-tech bioenergy power plants have a different perceptions compared to those experts who are working on appropriate rural technologies. In a 
developing country urban rural divide cannot be ignored. When we talk of bio-fuels the crop patterns and biodiversity of the area need to be considered. The prevalent traditional knowledge, practices and technologies have an impact on the perception of the target communities. In the context of European countries Harald Rohracher, et al., argue that 'it makes a difference whether we talk about these technologies and uses in Finland, England or in Spain - where different kinds of bioenergy usage may be dominant, different historic connotations and practices may exist'.

The haziness that surrounds the word 'Bioenergy' for a lay person, makes this concept difficult to understand. It may invoke varied images and awareness levels. Because of this multiplicity in meanings conducting a survey of perceptions is rendered more complex. Most of the surveys conducted in various countries point out this difficulty. ${ }^{12}$

A cursory scanning of project proposals on 'bioenergy' and the media reports point to another aspect, which makes it further hazy for a common citizens. The notion of bioenergy is enmeshed with and is placed within the debate of 'efficient use of resources', 'global warming', 'climate change', 'decreasing forest cover', 'depleting fossil fuel', 'carbon foot prints', 'sustainable development', 'renewable sources of energy', etc,. Within the discourse it is more fashionable to talk about solar, wind and tidal energies. The reason is simple and two fold. Firstly, relatively speaking, focus on bioenergy is a recent phenomenon. Research on wind and tidal energy research is much older. Secondly, during the past few decades large scale industries have emerged around the technologies developed in these older areas of renewable sources. Therefore, lobbies and economic interest groups to garner support for these technologies also developed in the past. Bioenergy projects remained within the domain of cottage industry (for example in India bio-gas plants) or were implemented through NGO's (for example smokeless stove). ${ }^{13}$

Across the world, opinion surveys, wherever they are conducted, reveal that bioenergy or biomass score low on the cognition map of the citizens as compared to solar or wind energy. For example a survey conducted in the cities of Rijeka and Zagreb, Croatia concludes that 'Citizens are relatively poorly informed both about the general aspects related to the production and consumption of energy and about specific aspects related to the use of renewable energy sources, and especially biomass and bioenergy'. ${ }^{14}$ Thornley and Prins Inform us that 'within the renewables sector the awareness of bioenergy is very low: $2 \%$ in a study in Ireland and $8 \%$ in one in the Netherlands. A UK study found that $85 \%$ of respondents wanted to increase renewables, $72 \%$ supported wind, with only $2 \%$ opposed; but only $16 \%$ supported biomass with $4.8 \%$ opposed - the vast majority just didn't know'. ${ }^{15}$ About $73 \%$ believed we should put more effort into using wind energy, while $79 \%$ believed we should put more effort into using solar energy. The support for bioenergy/biomass was lower about $45 \%$ believed we should put more effort into using it. ${ }^{16}$ A survey of British pubic reveals that when asked 'Have you heard of or read about any of the following in the past year?' only 10 percent of the respondent replied that they had heard of bioenergy. It ranked seventh with solar energy scoring as high as 69 percent. ${ }^{17}$ In short most surveys have confirmed 'awareness of bioenergy or biomass is generally rather low and wind energy or solar power are the main types of energy identified as renewable energies by a wider public'. In a survey done in Kenya, about $68.3 \%$ of all households reported use of firewood as the source of cooking fuel. ${ }^{18}$

The prevailing scenario has resulted in a situation where direct questions on bioenergy may not elicit desired response. Therefore most survey studies either tend to club renewable energy sources together or pose general question beside a few queries specific to various renewable technologies. It has been observed both in developing and developed countries that overwhelming people support non polluting technologies due to the fear of global warming. It has been pointed out earlier that the issues related to bioenergy are closely linked with a broader debate on sustainable development, climate change and pollution of the environment.

\section{Surveys in India}

India implemented a large number of projects in renewable energy supplies to rural areas. ${ }^{19}$ However, there has been a dearth of studies to find the peoples' perceptions and attitudes to these 'bioenergy' resources. Most of these projects were implemented without any needs assessment or consultations with the beneficiaries. Thus the 'felt needs' were never assessed, but the 'real needs' were imputed. In the area of public understanding of 'bioenergy' there is an urgent need to conduct large-scale surveys and studies in India. 
Ravindranath and Balachabdran report that what is not commercial is opaque to Indian policy makers. Ironically, in a country where 'non-commercial energy sources, predominantly fire wood, chips and dung cakes, contribute around $30 \%$ of the total primary energy consumed------ bioenergy does not figure in most energy analysis'. ${ }^{20}$ Studies carried out by TERI have shown 'that biomass delivers nearly $90 \%$ of the energy used in rural house hold and about $40 \%$ of energy used in urban household' (TERI 2010, 8) The traditional use of total biomass is large in quantum and widespread geographically. Rapid growth of industrialisation has started impinging upon the traditional modes and methods of energy use. The new efficient methods have not taken roots as yet. In this transitory phase, through which India is passing, a common citizen looks at the issue of bioenergy, as one that is closely linked to industrialisation. Without a matching shift in public understanding of 'bioenergy' and technical knowledge base it would be difficult to expect acceptability of new and efficient ways of generating and using bioenergy.

The closest one could get to survey on the public understanding of 'bioenergy' in India are a couple of surveys conducted by the authors during 2001 and 2007. During these two rounds of a large scale survey conducted in 2001 and 2007, four simple questions were posed to a sample of respondents - mainly related to effect of deforestation, air and water pollution, and effect of industrialization. The questions were asked to the respondents during Kumbh $2001^{21}(\mathrm{n}=3484)$ and Ardh-Kumbh $2007^{22}$ as well $(\mathrm{n}=3836)$ (see Table 1). The comparative analysis has been given in the following paragraphs.

\begin{tabular}{|l|l|}
\hline S No & Question \\
\hline 1 & What are the main causes of air pollution? \\
\hline 2 & What is/are the effect/s of industrialisation on environment? \\
\hline 3 & What is/are the effect/s of deforestation on environment? \\
\hline 4 & What are the main causes of water pollution? \\
\hline
\end{tabular}

Table 1. Questions asked during the surveys.

\section{What are the main causes of air pollution?}

Curiously, in a country where almost for every problem population growth is blamed, respondents did not think that population growth could be a cause of air pollution. In their cognitive structure no causal link exists between population growth and its likely impact on transport and industry. Transport or vehicular traffic as causes of air pollution were offered by 44.8 percent of the sampled population in 2007 while this percentage was marginally low (40.6 percent) in 2001. Industrialization as a cause of air pollution was reported by 28.0 percent of the respondents as compared to about 32.4 percent in 2001. About 27 percent responded 'don't know' while this percentage was comparatively low in 2001.

\section{What is/are the effect(s) of industrialisation on environment?}

The question related to rampant industrialization was aimed at probing the perception of respondents regarding its possible effects.

About 25 percent of the total sampled population responded that they don't know about it, while this percentage was 17.1 in 2001. About 37 percent in 2007 and 31 percent in 2001 responded that industrialization has caused water pollution. They may have experienced that factories release a lot of liquid waste, which goes to rivers and canals and cause pollution of water. As industrialization is associated with smoke coming out of the chimneys about 29 percent in 2007 and 33.4 percent in 2001 responded that industries cause air pollution. And it is clear from the analysis that about 65 percent of the respondents perceive that industrialization causes pollution. In addition to this 11.6 percent also responded that the fertile land has become barren due to industries. This response reveals that a substantial segment of the population quite clearly understands the causal relationship between industiralisation and soil pollution. The corresponding percentage of those who said that industrialisation causes soil pollution marginally decreased in 2007. The 'don't know' response also increased in 2007 compared to 2001 . 


\section{What are the effect(s) of deforestation on environment?}

An effort was made to assess the perception of the public regarding the possible effect of deforestation on the environment. In response to this question as high as 55.0 percent (during 2007) related deforestation to scarcity of rains while the corresponding percentage was 43.6 percent in 2001 survey. Percentage of people who said that 'floods' are caused by deforestation also increased marginally, while other responses such as 'no effect', gods unhappy' and 'don't know' decreased in percentage during 2007.

\section{What are the main causes of water pollution?}

Two specific questions were posed to the respondents on possible causes of water and air pollution. In response to causes of water pollution 37 percent responded that over population is the biggest cause, while this percentage was 34 percent during 2001. About 38.0 percent during 2007 and 35 percent during 2001 responded that proliferation of large number of factories units or industrialization, who throw their liquid and solid waste in rivers and canals, is the major cause of water pollution. A substantial segment of those who were interviewed said that they do not know the reason.

\section{Conclusion}

Traditionally biomass sources were the main sources of energy for human societies, particularly in developing countries. Currently, these sources are chief ingredients of energy needs of rural people in developing countries. Due to widespread recognition of adverse impacts of fossil fuels on climate change, there is a renewed interest in developing efficient technologies for use, conversion and regeneration of biomass based energy world-wide. In developing countries, bioenergy is derived from forests and non-forest resources and the markets for commercial utilisation through conversion, has not been developed.

The current focus on 'renewable' sources of energy has prompted researchers to study the public attitudes and behaviours toward use of bioenergy. However, there has been a paucity of survey research in this area, particularly in India.

\section{Notes and references}

1 World Commission on Environment and Development (WCED), Our Common Future, New York, Oxford University Press, (1987).

2 Ministry of Environment and Forests Government of India New Delhi (2009) India's Fourth National Report to the Convention on Biological Diversity.

3 Benard Muok (2010) PISCES Unlocking the Potential of Bioenergy to Improve Energy Access and -Livelihoods.

4 IPCC Synthesis Report AR4 - appendix.

5 For a sample of reviews on the content of climate change in mass media see:

M.T. Boykoff (2007), From convergence to contention: United States mass media representations of anthropogenic climate change science, Trans. Inst. Br. Geogr. NS 32: 477-489;

H.P. Peters (2008), Legitimizing Climate Policy: The "Risk Construct" of Global Climate Change in the German Mass Media, IJSC 3: $14-36$

S. Billett (2009), Dividing climate change: global warming in the Indianmass media, Climatic Change 99(1):1.

6 Environmental and Energy Study Institutefactsheet published on May 4, 2007, Polling information from April 2006 through April 2007: http://eesi.org/briefings/2007/energy_climate/5-4-07_Climate_polling/Climate Polling Fact Sheet_5.4.07.pdf accessed on October 15, 2010.

7 R.J. Bord, A. Fisher and R.E. O'Connor (1998), Public perceptions of global warming: United States and international perspectives, Climate Research 11: $75-84$.

8 Policy Innovation Systems for Clean Energy Security (PISCES) (2010), Status report on use of fuelwood in India.

9 Government of India Ministry of New \& Renewable Energy (2009), National Policy on Biofuels.

${ }^{10} \mathrm{H}$. Rohracher et al., Improving The Public Perception of Bioenergy in the EU, Final Report, http://ec.europa.eu/energy/res/sectors/doc/bioenergy/bioenergy_perception.pdf.

${ }^{11}$ D.T. Dwegener and J.R. Kelly (2008), Social Psychological Dimentions of Bioenergy Development and Public Acceptance, BioEnergy Research 1(2): 107-117.

${ }^{12}$ See reports of Euro Barometer and surveys conducted in Irland, Scandinavian countries, Netherlands, Kenya 
${ }^{13}$ For details see official web site of Government of India, Ministry of Non-conventional Energy Sources.

${ }^{14}$ V. Segon et al. (2004), Raising the Awareness of Bioenergy Benefits: Results of two Public Surveys on Attitudes, Perceptions and Knowledge, http://www.task29.net/assets/files/reports/Segon 2004.pdf.

${ }^{15}$ P. Thornley and W. Prins (2008), Public Perceptions and Bioenergy Some remarks in preparation of the workshop scheduled for the Thermalnet meeting in Vicenza, http://www.thermalnet.co.uk/docs/Barriers\%20Precisfinal.pdf.

${ }^{16}$ Report, Public and stakeholder attitudes towards energy, environment and CCS, AGS Pathways report 2007:E2, Pathways to Sustainable European Energy Systems, Ags, The Alliance for Global Sustainability, Göteborg (2007).

${ }^{17}$ T.E. Curry et al. (2005), A Survey of Public Attitudes towards Energy \& Environment in Great Britain, Laboratory for Energy and the Environment, Massachusetts Institute of Technology, U.S.A.

${ }^{18}$ T. wa Gathui and W. Ngugi (2010), Bioenergy and Poverty in Kenya - Attitudes, Actors and Activities, Prepared for Pisces by Practical Action Consulting in Eastern Africa.

${ }^{19}$ TERI (2010), Biomass energy in India. A background paper prepared for the International Institute for Environment and Development (IIED) for an international ESPA workshop on biomass energy, 19-21 October 2010, Parliament House Hotel, Edinburgh. TERI, New Dehli, India.

${ }^{20}$ P. Balachandra and N.H. Ravindranath (2009), Energy efficiency in India: Assessing the policy regimes and their impacts, Energy Policy, Elsevier Science.

${ }^{21}$ G. Raza and S. Singh (2002), Tryst with Science: Shift in PUS over a Decade - Study based on Survey Conducted during Mahakumbh 2001 at Allahabad, NISTADS.

${ }^{22}$ G. Raza and S. Singh (2007), Science and Public: Study Report based on Survey Conducted during Ardh-kumbh, NISTADS.

\section{Authors}

Gauhar Raza, working as a Senior Scientist at NISCAIR (CSIR), India, on Public attitude towards and understanding of science. He has organised more than 20 survey studies in India and abroad on PUS. He was instrumental in suggesting 'cultural model' of public understanding of science. In addition, he is also involved in making films on scientific issues and writing poetry. E-mail: gauhar_raza@yahoo.com.

PVS Kumar is working as a Senior Scientist at NISCAIR (CSIR), India. His doctorate degree is on demographic studies. He is an expert on information technology with a special interest on public understanding of environmental studies. E-mail: kumarpatnam@gmail.com.

Surjit Singh has been working as Researcher at NISCAIR (CSIR), India, in the area of public understanding of science and has been involved in large-scale survey studies for the last 20 years. He is also involved in science communication among school children and public understanding of HIV/AIDS related issues among public. E-mail: ssdabas@yahoo.com.

How to cite: G. Raza, P.V.S. Kumar and S. Singh, Public understanding of environment and bioenergy resources, Jcom 10(03) (2011) A03. 